Recorregut de recerca geològica i geoambiental per la comarca de l'Anoia (Alta Segarra), tot fent una fillola final pel Solsonès: des dels Prats de Rei a Calaf, Durfort, Aleny, Sant Pesselaç i a les Basses

Josep Maria Mata-Perelló

Joaquim Sanz Balagué

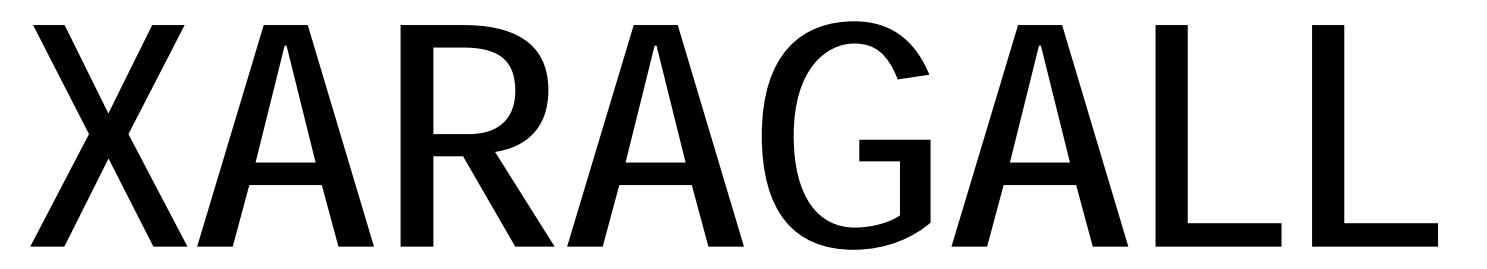

REVSTA DE CIÈNCIES DE LA CATALUNYA CENTRAL

n. 12

DESEMBRE 2014 


\title{
RECORREGUT DE RECERCA GEOLÒGICA I GEOAMBIENTAL PER LA COMARCA DE L'ANOIA (ALTA SEGARRA), TOT FENT UNA FILLOLA FINAL PEL SOLSONĖS: DES DELS PRATS DE REI A CALAF, DURFORT, ALENY, SANT PESSELAÇ I A LES BASSES
}

\author{
Josep Maria Mata-Perelló \\ Museu de geologia Valentí Masachs, Escola Politècnica Superior d'Enginyeria de Manresa \\ (EPSEM), Universitat Politècnica de Catalunya · BarcelonaTech (UPC), 08272 Manresa, Spain
}

Joaquim Sanz Balagué

Departament d'Enginyeria Minera i Recursos Naturals (EMRN), Escola Politècnica Superior d'Enginyeria de Manresa (EPSEM), Universitat Politècnica de Catalunya . BarcelonaTech (UPC), 08272 Manresa, Spain

Paraules clau: Depressió Geològica de l'Ebre, Materials terciaris, Materials quaternaris, Patrimoni miner

\section{Resum}

Itinerari realitzat el 25 de gener de 2014. En aquesta ocasió, es realitzarà un recorregut geològic que discorrerà en la seva totalitat per diferents indrets de la Depressió Geològica de I'Ebre; i més concretament pels sectors corresponents a la seva Depressió Central. D'aquesta manera, tot el recorregut transitarà entre afloraments dels materials terciaris (de l'Oligocè) i quaternaris que reblen aquesta depressió.

Com a tret fonamental, la totalitat del recorregut transitarà per la Conca Lignitífera de l'alta Segarra, situada íntegrament dintre de la Formació Tàrrega, de l'Oligocè.

Per altra banda, la totalitat del recorregut transitarà per la comarca de l'Anoia (i més concretament per la seva subcomarca de I'Alta Segarra). Així, s'iniciarà als Prats de Rei, passant ben aviat per Calaf (la capital de la subcomarca i de la conca lignitífera). Malgrat això el recorregut finalitzarà a les Bases, situada actualment dintre de la comarca del Solsonès, tot $\mathrm{i}$ que forma part de la Conca Lignitífera de l'Alta Segarra i que en realitat pertany a la subcomarca. 


\section{Objectius fonamentals}

Els objectius fonamentals que es pretenen aconseguir en aquest itinerari, es poden concretar en els següents aspectes generals:

1. Observació i descripció dels materials terciaris (exclusivament del Paleogen, i més concretament de I'Oligocè) de la Depressió Geològica de l'Ebre (i més exactament de la seva Depressió Central). Així, el recorregut de l'itinerari discorrerà totalment entre els afloraments del Complex Lacustre de la Segarra (amb terrenys que pertanyen a la Formació Tàrrega, de l'Oligocè).

2. Observació de les estructures locals de la Depressió Geològica de l'Ebre, al llarg del recorregut de l'itinerari.

3. Observació i reconeixement de les mineralitzacions associades a les alteracions de la PIRITA primària inclosa entre els nivells carbonosos de la Conca Lignitífera de l'Alta Segarra.

4. Observació de les explotacions relacionades amb els materials anteriors, com les següents, d'acord amb el sentit de la marxa de l'itinerari.

4A) Les explotacions dels nivells calcolutítics de la Formació Tàrrega, que veurem a Calaf $\mathrm{i}$ a Durfort.

4B) Les explotacions dels materials carbonosos, que trobarem prop dels Prats de Rei, Durfort, Aleny i les Bases, entre els materials de la Formació Tàrrega.

5. En tots els casos, a les explotacions anteriors, s'observaran les restauracions efectuades en elles, si s'escau.

6. S'observaran, al llarg de tot el recorregut, els diferents elements relacionats amb el Patrimoni Geològic i Miner-

\section{Antecedents}

Pel que fa al recorregut del present itinerari, existeixen diferents antecedents bibliogràfics. Entre ells farem esment dels següents: pel que fa a la totalitat del recorregut; ja que en bona part constitueix una primícia. Hi ha, però, alguns antecedents parcials, relatiu a algun dels trama inicials; entre aquests farem esment dels següents: Mata-Perelló (1996, 1997. 1999a. 1999b, 2005, 2007a, 2007b, 2010, 2011 i 2014).

Pel que fa a la descripció de les mineralitzacions, seguirem fent esment d'alguns altres treballs nostres: Mata-Perelló (1990 i 1991); el primer relatiu a la comarca d'Anoia, el segon al conjunt de les mineralitzacions catalanes.

I, finalment, pel que fa a l'estructura geològica de la zona per la qual discorre l'itinerari, farem esment dels treballs de: Guimerà et altri (1982) i de Riba et altri (1976). També farem esment d'un treball nostre: Mata-Perelló (1985).

Tots aquests treballs referenciats, i d'altres, figuren esmentats per ordre alfabètic a l'apartat dedicat a la BIBLIOGRAFIA. 


\section{Recorregut de l'itinerari}

El recorregut de l'itinerari discorrerà íntegrament per la comarca d'Anoia (per la subcomarca de I'Alta Segarra), des de principi a fi. Així, s'iniciarà a la població dels Prats de Rei, per on es farà la primera aturada. I tot seguit, el recorregut es dirigirà cap a la propera població de Calaf (la capital de la subcomarca). S'hi anirà seguint la carretera autonòmica C - 1412A. En arribar a Calaf es farà una nova aturada.

Després, seguint per la mateixa carretera, el recorregut es dirigirà cap a les immediacions de Durfort, per on es farà una nova aturada, dintre del terme de Calonge de Segarra. Després caldrà tornar enrere, arribat quasi a I'Eix Transversal, però abans es trobarà un camí de terra que es dirigeix fins prop d'Aleny i de la carretera local B - 300. Seguint aquest camí de terra, fent filloles es faran dues noves aturades.

Posteriorment, s'anirà cap a l'esmentat poble d'Aleny, seguint ara la carretera local B - 300 . Abans d'entrar al poble es farà una nova aturada. Tot seguit, seguint aquesta carretera, s'anirà cap a Sant Pesselaç (Sant Pere dels Arç), per on es faran dues noves aturades prop del poble.

Finalment, caldrà tirar enrere, per tal de continuar pel camí que es dirigeix cap a les Basses, per on es farà la darrera aturada, dintre de la subcomarca i de la Conca Lignitífera de l'Alta Segarra: però també dintre del Solsonès.

\section{Advertiments previs}

Com en altres recorreguts de RECERCA GEOLÒGICA I MINERALÒGICA... si es disposa del temps suficient, poden efectuar-se passant per totes les parades i filloles. En cas contrari, recomanem prescindir de les anomenades PARADES - CONDICIONALS.

També cal tenir en conte que part del recorregut, tant a l'inici de l'itinerari, com als seus darrers trams, es realitzarà per camins de terra, per la qual cosa caldrà prendre les degudes precaucions. En aquest recorregut, caldrà fer diversos recorreguts per camins de terra en bon estat de conservació, generalment.

Cal tenir, com sempre, una cura molt especial de respecte a la natura, al llarg de tot el recorregut de l'itinerari, i també fora d'ell. 


\section{Descripció de l'itinerari}

Com de costum, estructurarem el recorregut de I'itinerari en una sèrie de PARADES, que anirem veient. En cadascuna d'aquestes aturades farem un breu comentari (geològic 0 mineralògic, segons s'escaigui). En cada cas indicarem, entre parèntesi, el full topogràfic on es troba l'aturada. En aquest cas, el recorregut de l'itinerari s'inclourà dintre d'un sol full, del "Mapa Topográfico Nacional", realitzats a l'escala 1:50.000 per l'"I.G.C. de España"; concretament del $\mathbf{3 6 2}$ (antigament dit de Calaf i ara de Sant Joan de Vilatorrada). Tanmateix, si s'escau, es pot utilitzar el Mapa Topogràfic Comarcal d'Anoia, editat per I'Institut Cartogràfic de Catalunya. Així doncs, la relació de les aturades, que composen el recorregut d'aquest itinerari és la següent.

\subsection{Parada 1 - CONDICIONAL. MINA DE LIGNIT DELS PRATS DE REI, (terme municipal dels Prats de Rei, comarca d'Anoia, subcomarca de l'Alta Segarra). (Full 390).}

El recorregut l'iniciarem a la població dels Prats de Rei. Des d'aquí caldrà remuntar el riu Anoia, pel seu cantó dret. A uns 1'5 Km del poble trobarem l'escombrera d'una antiga mina de lignit. Aquí farem la primera aturada d'aquest itinerari. Així, des de la parada anterior haurem recorregut uns $2 \mathrm{Km}$, aproximadament.

En aquest recorregut, hem anat trobant afloraments dels nivells de calcolutites grisenques i de nivells carbonatats. Aquests materials formen part de la Formació Tàrrega i es situen dintre del Complex Al.luvial de la Segarra. Per d'altra banda, aquests materials presenten un clar cabussament cap el Nord i formen part del flanc meridional del Sinclinal de Calaf, on estem ara situats.

En aquest indret hi havia una antiga mina de lignit. Aquests lignits es situen dintre dels materials de la Formació Tàrrega. Es tracta d'uns lignits molt pobres i alhora molt ferruginosos. Així es fàcil veure mineralitzacions secundàries de ferro, amb presència de GOETHITA (en forma de LIMONITA) i de MELANTERITA. També és fàcil veure GUX, que s'ha format com a conseqüència de l'atac de l'Àcid Sulfúric (originat per l'alteració de la PIRITA primària) sobre la CALCITA, present entre les calcolutites.

Pel que fa a la mina, cal dir que no va ésser gaire important. Formava part de la Conca lignitífera de Calaf. Ara sols es pot veure l'escombrera. (fotografia 1). 


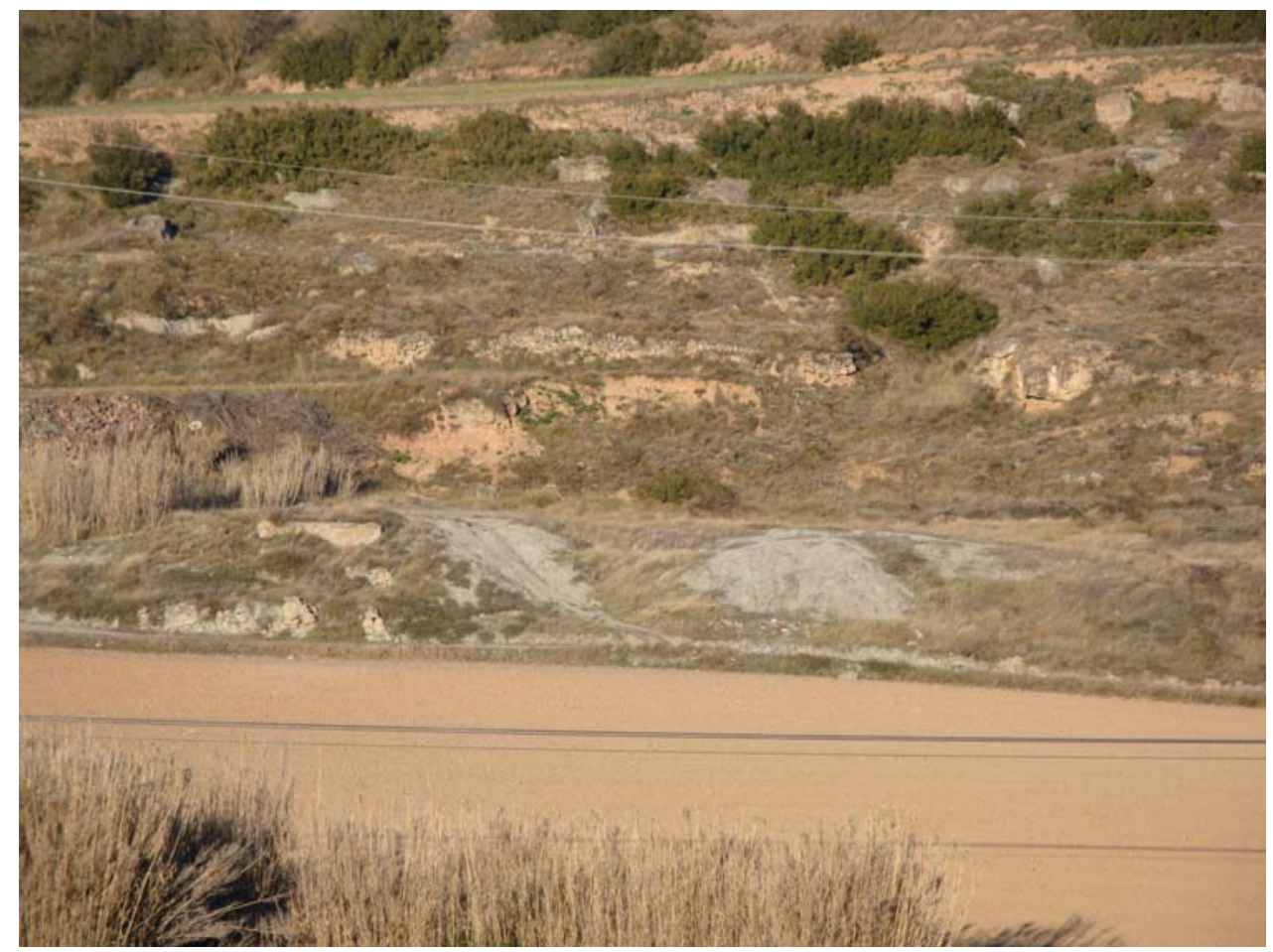

Fotografia 1. Al centre de la fotografia, encara es poden veure les restes de l'escombrera de la mina de lignit dels Prats de Rei

\subsection{Parada 2. EXPLOTACIONS DE CALCOLUTITES DEL TURÓ DE SANT SEBASTIÀ, (terme municipal de Calaf, comarca d'Anoia, subcomarca de I’Alta Segarra). (Full 362).}

Des de la parada anterior, cal continuar cap al Nord, per tal d'arribar al poble de Calaf, la capital de la subcomarca. Per tal d'anar-hi, cal seguir la carretera autonòmica C - 1412A. En arribar-hi, cal adreçar-se cap a les properes explotacions de calcolutites. En aquest indret, prop de les explotacions, i després de recórrer uns $2 \mathrm{Km}$, és on ens caldrà fer la present aturada.

En aquest recorregut, hem anat tallant els materials calcolutítics ja esmentats a la parada anterior. I, precisament en aquest lloc, aquests es troben en explotació, per tal d'ésser utilitzats en la fabricació de totxos i de ceràmica.

Pel que fa a l'explotació, cal dir que es força gran, i els materials extrets es porten cap a la propera fàbrica, situada a la bora de Calaf. Finalment, cal dir que per accedir a l'explotació, cal tenir necessàriament l'autorització de l'empresa (Ceràmiques Calaf S.A.).

Per d'altra banda, en aquest recorregut, ben prop de Calaf, haurem trobat una explotació de calcolutites. (fotografia 2). 


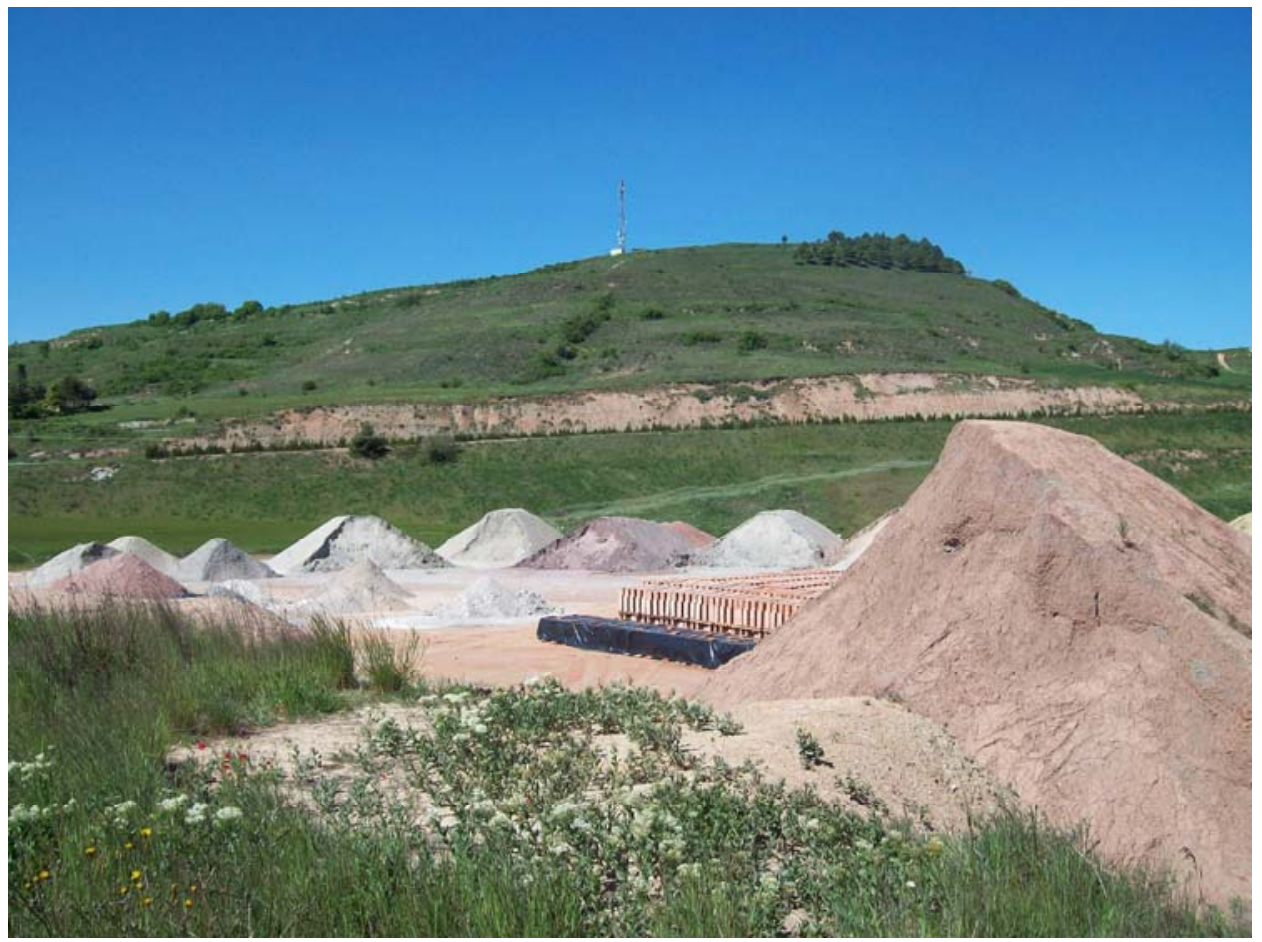

Fotografia 2. Vista general de Ceràmiques Calaf. Es poden veure argiles procedents de diferents indrets

\subsection{Parada 3. IMMEDIACIONS DE LA CRUÏLLA ENTRE LA CARRETERA AUTONÔMICA C - 1412A I L'EIX TRANSVERSAL, (Durfort, terme municipal de Calonge de Segarra, comarca d'Anoia, subcomarca de I’Alta Segarra). (Full 362).}

Des de la parada anterior, caldrà sobrepassar la població de Calaf, seguint la carretera autonòmica C - 1412A. En arribar a les immediacions de la cruïlla elevada entre la carretera anterior l'Eix Transversal, podem fer unes nova aturada, a menys de $1 \mathrm{Km}$, de l'anteriorment realitzada.

En aquest breu recorregut, hem trobat afloraments dels materials esmentats a l'aturada anterior. Així, s'han fet paleses les calcolutites (generalment ocres) de la Formació Tàrrega, del Complex Al/luvial de la Segarra. Aquests són també els materials que afloren on ara estem situats.

Des d'aquest lloc, mirant cap a Durfort i cap a Mirambell (cap a ponent, fonamentalment), es poden veure els relleus cenozoics, tot formant un interessant "relieve en cuesta". (fotografia 3). 


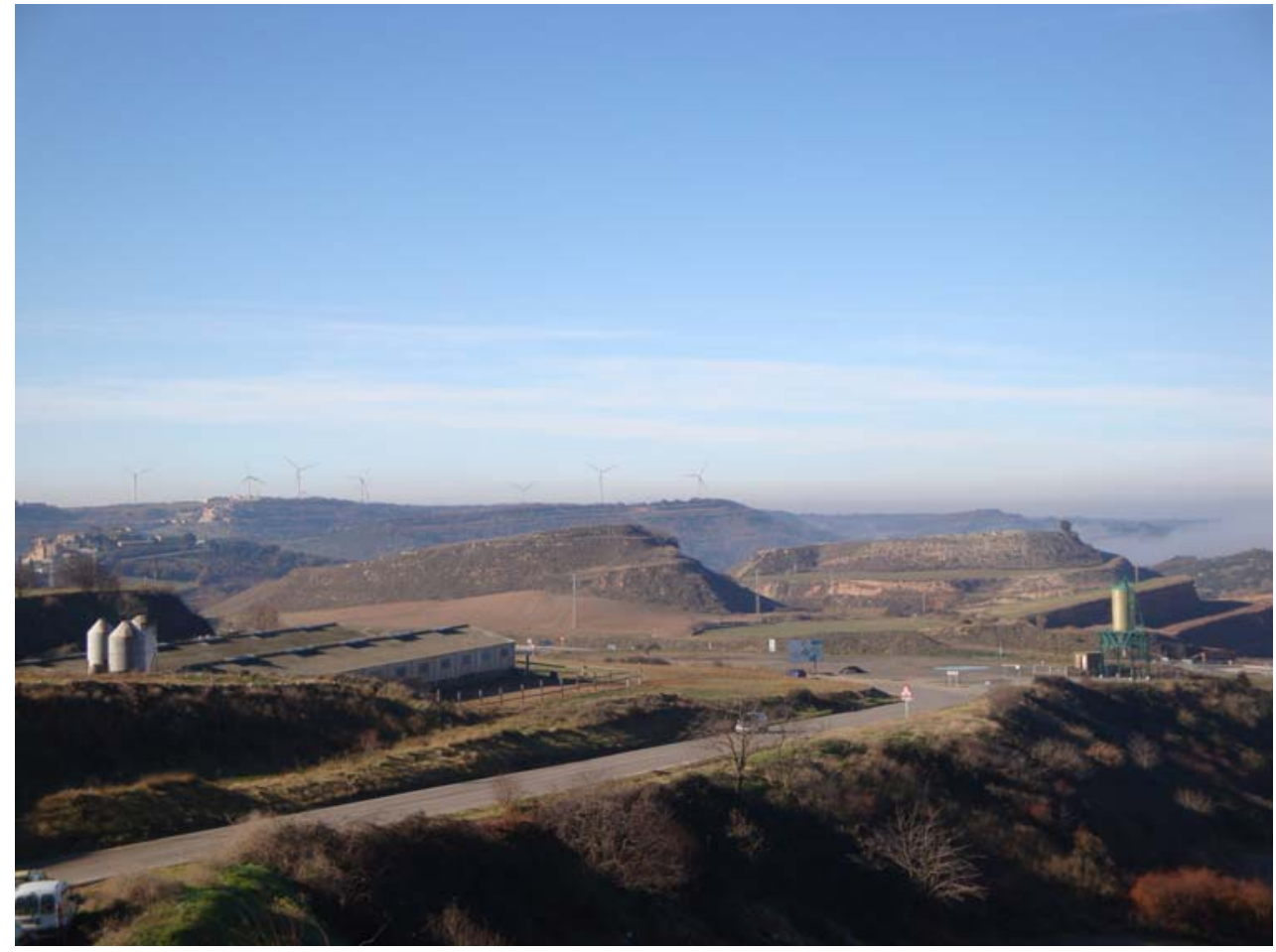

Fotografia 3. "Relieves en cuesta" prop de la població de Durfort

Per altra banda, des d'aquest indret, mirant cap a la població d'Aleny, es pot veure part de I'antiga Conca Lignitífera de la Segarra, per on circularem en algunes de les properes aturades.

\subsection{Parada 4 - CONDICIONAL. INSTAL-LACIONS I EXPLOTACIONS DE GRES CATALÁN, (Durfort, pertany al terme de Calonge de Segarra, comarca d'Anoia, subcomarca de I'Alta Segarra). (Full 362).}

Des de la parada anterior, caldrà continuar cap el Nord, seguint la carretera autonòmica $\mathrm{C}$ 1412A. Ben aviat arribarem a les antigues instal-lacions de Gres Catalan (actualment tancades). Prop hi ha unes antigues explotacions de calcolutites. Per aquest indret farem una nova aturada, a poc més de $1 \mathrm{Km}$ de l'anteriorment realitzada.

Com als recorreguts anteriors, en aquest trajecte hem trobat afloraments dels materials esmentats a les aturades anteriors. Es tracta de les calcolutites ocres de la Formació Tàrrega. Aquests materials formen part del Complex Al.luvial de la Segarra.

En aquest indret hi ha la fàbrica aturada de l'empresa Gres Catalan, de Ceràmiques Sugranyes. A l'altra banda de la carretera hi havia una sèrie d'explotacions de les calcolutites se la Formació Tàrrega. 


\subsection{Parada 5 - CONDICIONAL. ESCOMBRERA DE L'ANTIGA MINETA DEL TORRENT DE TRIBOLVÍ, , (Durfort, pertany al terme de Calonge de Segarra, comarca d'Anoia, subcomarca de I’Alta Segarra). (Full 362).}

Des de la parada anterior, caldrà retornar per la carretera autonòmica $C-1412 \mathrm{~A}$, fins arribar a la primera rotonda elevada que hi ha sobre I'Eix Transversal. Immediatament cal tornar a sortit per la carretera per la que hem arribat, en sentit contrari. A uns 20 metres de la rotonda, trobarem un camí de terra per l'esquerra, que ens caldrà agafar. Seguint per aquest camí, després de sobrepassar dues granges arribarem a una escombrera situada al costat d'un torrentet. Aquí farem una nova aturada, a uns 2'5 Km de l'anterior.

En aquest recorregut, hem trobat afloraments dels materials esmentats a les aturades anteriors. Aquests materials, amb nivells de calcolutites ocres, també afloren per aquest indret. Aquests materials pertanyen, com tots els que hem anat trobant, a la Formació Tàrrega, de I'Oligocè.

En aquest indret hi ha les restes d'una antiga escombrera. Aquesta estava relacionada amb una mineta on s'explotaven els lignits situats entre els materials abans esmentats de l'Oligocè. (fotografia 4).

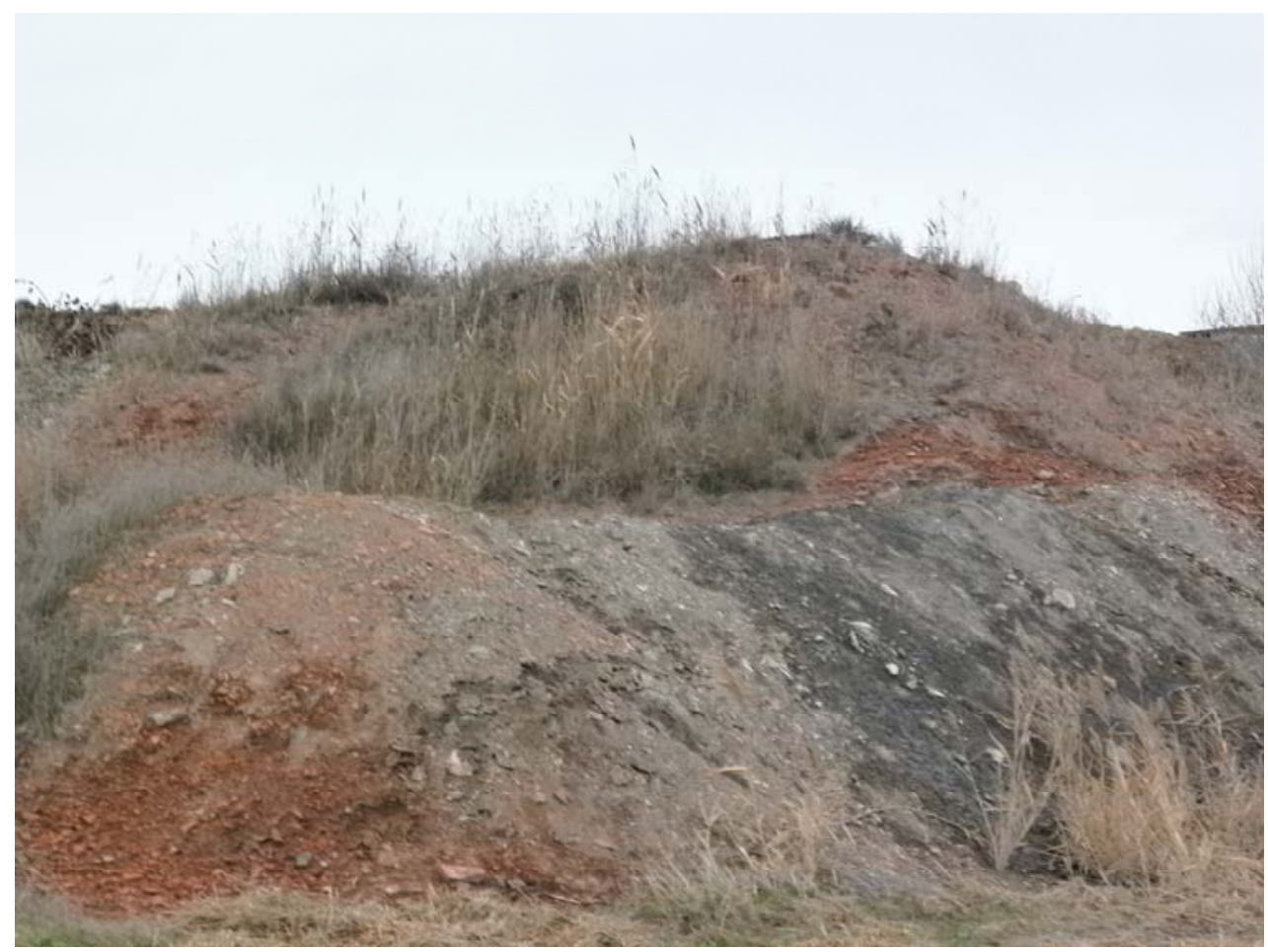

Fotografia 4. Antiga escombrera de la Mina de Lignit del Torrent de Tribolvi. Calonge de Segarra 
Mirant l'escombrera, es poden veure restes del lignit i també de la roca encaixant. Amb els lignits es troben òxids de ferro (especialment GOETHITA, en forma de LIMONITA). També es troben sulfats de ferro (la MELANTERITA). Tots aquests minerals s'han format a partir dels sulfurs de ferro presents als lignits (PIRITA i MARCASSITA, fonamentalment). I tanmateix, també es troba GUIX, format en els processos d'alteració de la PIRITA, en presència de CALCITA. Ocasionalment, també hi ha MULLITA, formada en els processos de cocció de les argiles en la combustió espontània dels lignits a la intempèrie.

\subsection{Parada 6. ANTIGA MINA DE LIGNIT A CEL OBERT D’ALENY, (Aleny, terme municipal de Calonge de Segarra, comarca d'Anoia, subcomarca de l'Alta Segarra). (Full 362).}

Després d'efectuar I'aturada anterior, cal seguir pel camí de terra, anant cap a ponent. En arribar al trencall de les Quadres, caldrà agafar-lo, sobrepassant la casa per l'esquerra. Seguint per aquest trencall arribarem a un barranc (el Barranc d'Aleny) per on havia una antiga explotació de lignit a cel obert. Aquí farem una nova aturada, a poc més de 1 '5 $\mathrm{km}$ de I'anterior.

En aquest recorregut, hem trobat (una vegada més) els materials esmentats als recorreguts cap a les parades anteriors. Així, hem trobat calcolutites i calcàries de la Formació Tàrrega en tot el trajecte. Tanmateix es troben lignits, els quals es van explotar.

En aquest indret va haver-hi una antiga explotació minera a cel obert. Aquesta explotació va generar una gran polèmica pel seu impacte. Finalment va tancar. Anys més tard es va procedir a la restauració mediambiental. Aquesta restauració es pot veure a l'indret de l'aturada. (fotografia 5).

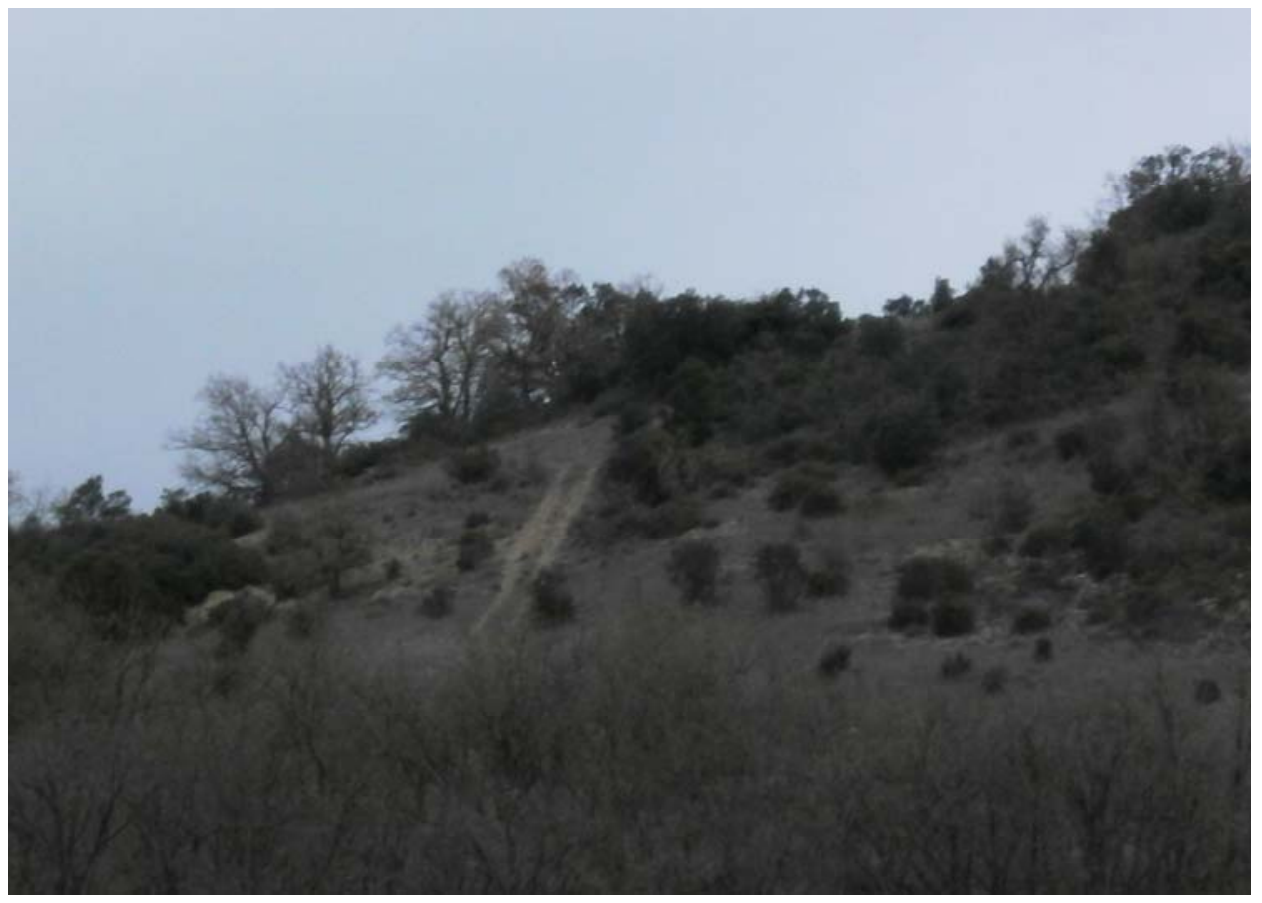

Fotografia 5. Antiga explotació a cel obert d’Aleny, actualment restaurada. 


\subsection{Parada 7. ENTRADA AL POBLE D’ALENY, (Aleny, terme municipal de Calonge de Segarra, comarca d'Anoia, subcomarca de I’Alta Segarra). (Full 362).}

Després de realitzar la parada anterior, caldrà retornar al camí principal, anant cap a llevant. Aviat arribarem a la carretera local B - 300, la qual es dirigeix cap al poble d'Aleny. A l'entrada al mateix, podem fer una nova aturada. Així, des de la parada anterior, haurem recorregut poc més de $2 \mathrm{Km}$.

També, en aquest recorregut, hem continuat trobant afloraments dels materials calcolurtítics i carbonats de la Formació Cardona. Efectivament, ens trobem situats entre els afloraments oligocènics del Complex Al.luvial de las Segarra. .

En aquest indret, situat a l'entrada del poble, es pot fer una observació del flanc septentrional del lax Sinclinal de Calaf, Aquest flanc es pot veure gràcies al sentit cap el Sud dels diferents relieves en cuesta dels materials oligocènics. Cal recordar que a la primera aturada, per les immediacions dels Prats de Rei, hem estat circulant pel flanc meridional. I tanmateix, en tot el recorregut fins ara hem deambulat per l'artesa del plec. (fotografia 6).

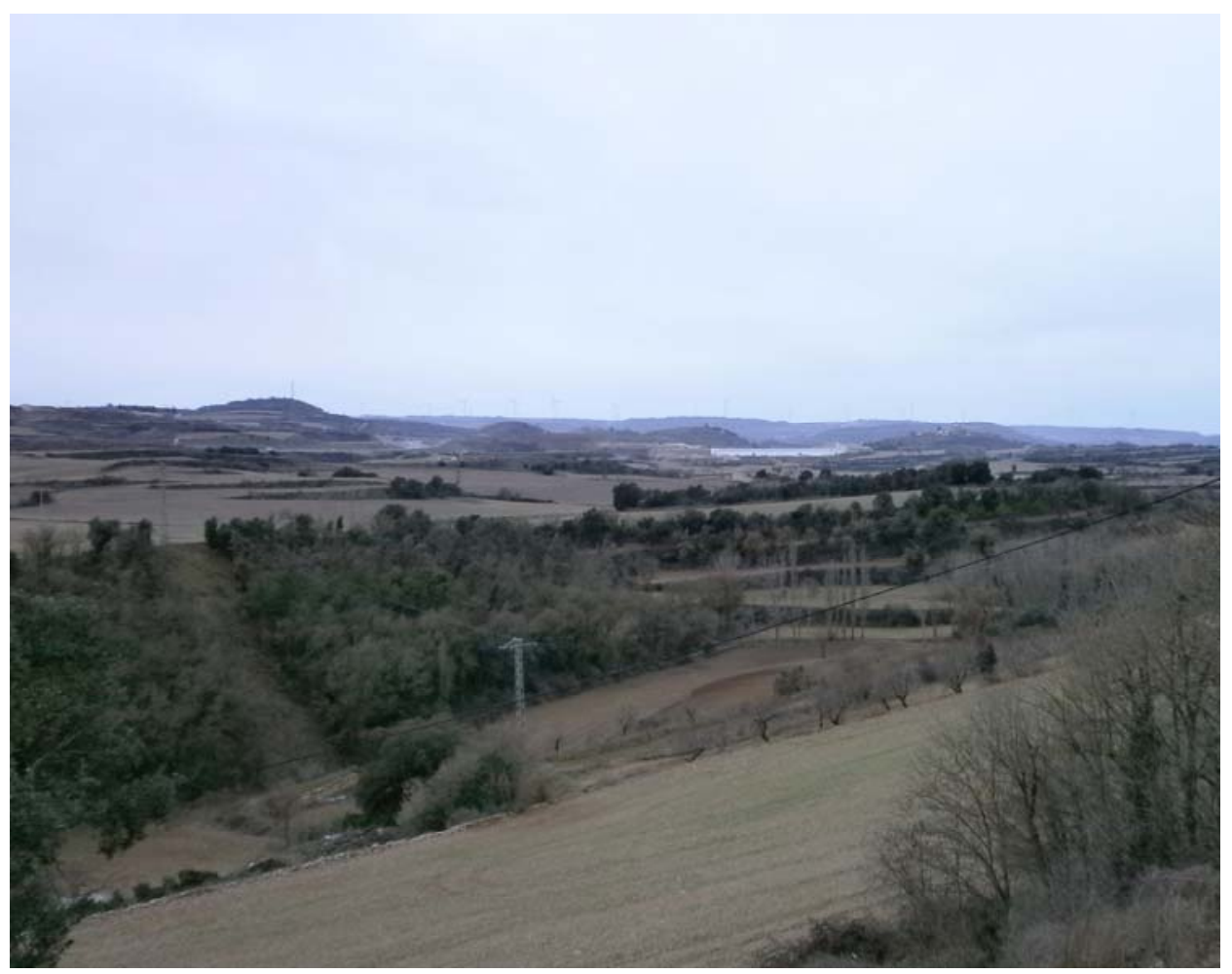

Fotografia 6. Aspecte des d'Aleny, del flanc septentrional del Sinclinal de Calaf.

S'observa per la inclinació cap el Sud dels camps (situats sobre superfícies estructurals) i també de les pendents suaus dels relieves en cuesta, inclinats cap el Sud, cap a l'esquerra de la fotografia.

Tot i així, la inclinació d'aquest flanc septentrional és més acusat, ja que ve a coincidir amb el flanc meridional de l'Anticlinal de Súria, que veurem dintre de les dos properes aturades d'aquest itinerari. 


\subsection{Parada 8 - CONDICIONAL. LA MINETA, (Sant Pesselaç, terme municipal de Calonge de Segarra, comarca d'Anoia, subcomarca de I’Alta Segarra). (Full 362).}

Des de la parada anterior, cal seguir cap el Nord per la carretera local B - 300, la qual es dirigeix ara cap a Sant Pesselaç (Sant Pere dels Arç) i posteriorment cap a Pinós. A nosaltres ens interessa arribar fins a les immediacions del primer poble esmentat, deixant a la dreta el trencall de les Bases (cap on anirem més tard). Poc abans d'arribar al primer poble esmentat, trobarem un caminet (a ma dreta de la carretera), el condueix cap a una antiga mineta de lignit. Aquí farem una nova aturada, a uns 3'5 Km, de l'anterior, aproximadament.

En aquest recorregut, hem anat trobant afloraments dels materials esmentats a les aturades anteriors. Aquests materials són també els que es troben per l'indret de la present aturada.

En aquest lloc hi havia una mineta. En ella s'explotaven subterràniament els nivells lignitíferes oligocènics de la Formació Tàrrega. En aquest cas, cal fer esment de les grans quantitats de GUIX FIBRÒS i de GUIX LAMINAR, formats a partir dels processos d'oxidació de la PIRITA incloses entre els lignits. En aquestes oxidacions es va formar àcid sulfúric, el qual va atacar a la CALCITA inclosa entre els sediments, originant-se així la formació del GUIX.

\subsection{Parada 9. IMMEDIACIONS DE LA CARRETERA A PINÓS, SORTIDA DE SANT PESSELAÇ, (Sant Pesselaç, terme de Calonge de Segarra, comarca d'Anoia, subcomarca de l’Alta Segarra). (Full 362).}

Després de realitzar la parada anterior, cal acabar d'arribar fins el poble de Sant Pesselaç (de Sant Pere del Arç). Tot seguit, cal continuar per la carretera local B - 300, la qual es dirigeix cap a Pinós (ja situat dintre de la comarca del Solsonès). En sortir de Sant Pesselaç, trobarem per l'esquerra la carretereta procedent de Calonge de Segarra (la capital municipal). A nosaltres, ens caldrà continuar per la carretera local B - 300, però a uns 100 metres de la cruïlla anterior, trobarem un camí per l'esquerra, que ens caldrà agafar, a uns 50 metres del seu inici, farem una nova aturada. Així, des de la parada anterior, haurem recorregut poc més de 1'5 Km, per tal d'arribar fins aquí.

En aquest recorregut, hem continuat trobant afloraments dels materials esmentats a les aturades anteriors. Tot i això, ara s'hauran fet palesos uns nivells més blanquinosos, amb presencia de calcolutites i alguns nivells de calcàries. Aquests materials formen part de la Formació Súria i es podrien incloure dintre del Complex de Sanaüja. Entre aquests afloraments també es fan palesos nivellets de guix.

En arribar a aquest indret, mirant cap a llevant, podem veure el flanc meridional de la Serra de Castelltalllat. Aquest flanc ve a coincidir amb el flanc meridional de I'Anticlinal de Súria. Com es recordarà, es tracta d'un plec asimètric, que constitueix l'esmentada serra. Així doncs, ara estem sobre aquest flanc meridional de l'anticlinal, que ve a coincidir amb el flanc septentrional del Sinclinal de Calaf, del que n'hem parlat anteriorment. (fotografia 7). 


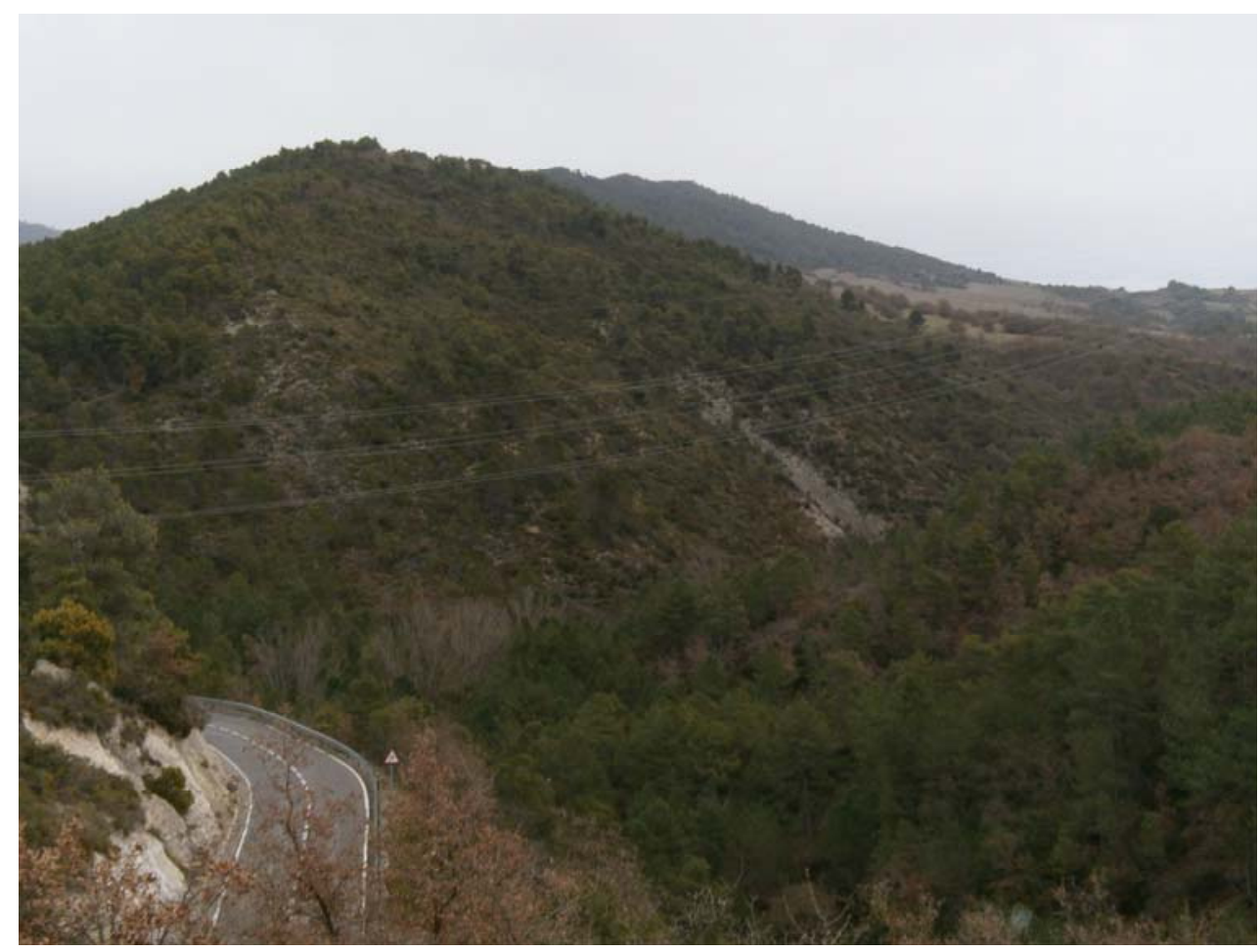

Fotografia 7. Flanc meridional de la Serra de Castelltallat, des de les immediacions de Sant Pesselaç Aquest es també el flanc de l'Anticlinal de Súria.

Per sota, a la carretera afloren les calcolutites, calcaries i guixos de la Formació Súria, te tonalitats grisenques.

\subsection{Parada 10. ANTIGA MINA DE LIGNIT DE LES BASSES, (les Basses, terme municipal de Pinós, comarca del Solsonès, subcomarca de I’Alta Segarra). (Full 362).}

Després de fer l'aturada anterior, cal tornar enrere cap a Sant Pesselaç (o Sant Pere de l'Arç), tot seguint per la carretera local B - 300 ara anant en sentit invers a l'originàriament seguit. Caldrà sobrepassar el poble, anant cap a Calaf. Tot i així, a poc més de $0^{\prime} 5 \mathrm{Km}$ del poble, trobarem un trencall per l'esquerra, el qual es dirigeix (entre altres llocs) cap a les Bases. Ens caldrà anar-hi per un camí de terra en molt bones condicions. En arribar-hi, després d'un recorregut proper als $2 \mathrm{Km}$ des de la darrera aturada, n'efectuarem una altra: la darrera $d^{\prime}$ aquest itinerari.

Cal dir que en aquest recorregut, cap al final del mateix, hem deixat l'actual comarca d'Anoia, per entrar a la del Solsonès. Tot $i$ així, aquest indret es situa plenament dintre de la subcomarca de l'Alta Segarra. De fet, fins a la remodelització comarcal era del terme de la Molsosa i aquest es situava dintre d'aquesta comarca, tot i pertànyer a la província de Lleida. Per d'altra banda, el llogarret de les Basses es situa plenament dintre de la Conca lignitífera de Calaf.

Per altra banda, en aquest recorregut hem anat trobant, com en tots els recorreguts anteriors d'aquest itinerari, hem anat trobant afloraments de les calcolutites i també de nivells carbonatats oligocens. Aquests materials sovint tenen nivells de lignits, com a l'indret de la present aturada, Aquests materials formen part de la Formació Tàrrega i śinclouen dintre del 
Complex Al-luvial de la Segarra. De fet, durant tot el recorregut de l'itinerari no hem abandonat mai aquests materials.

Com a algunes de les aturades anteriors, apareixen uns nivells de lignits cenozoics, de I'Oligocè. Aquests lignits es troben intercalats entre els materials de la Formació Tàrrega. Generalment, es tracta de lignits molt ferruginosos, amb presencia de PIRITA, MARCASSITA i MELNIKOVITA. Generalment, per l'alteració d'aquests sulfurs s'han format òxids (com la GOETHITA en forma de LIMONITA i sulfats de ferro (com la MELANTERITA).

Tanmateix, per l'alteració dels sulfurs s'ha originat Àcid Sulfúric. Aquest ha tacat a la CALCITA present entre les roques encaixonant, conduint cap a la formació de GUIX (generalment laminar o fibrós).

Així, per aquests indrets hi ha diverses explotacions de lignits, les quals es troben situades en torn al caseriu de les Bases. Es tracta de petites explotacions, actualment enrunades, en bona part. (fotografia 8).

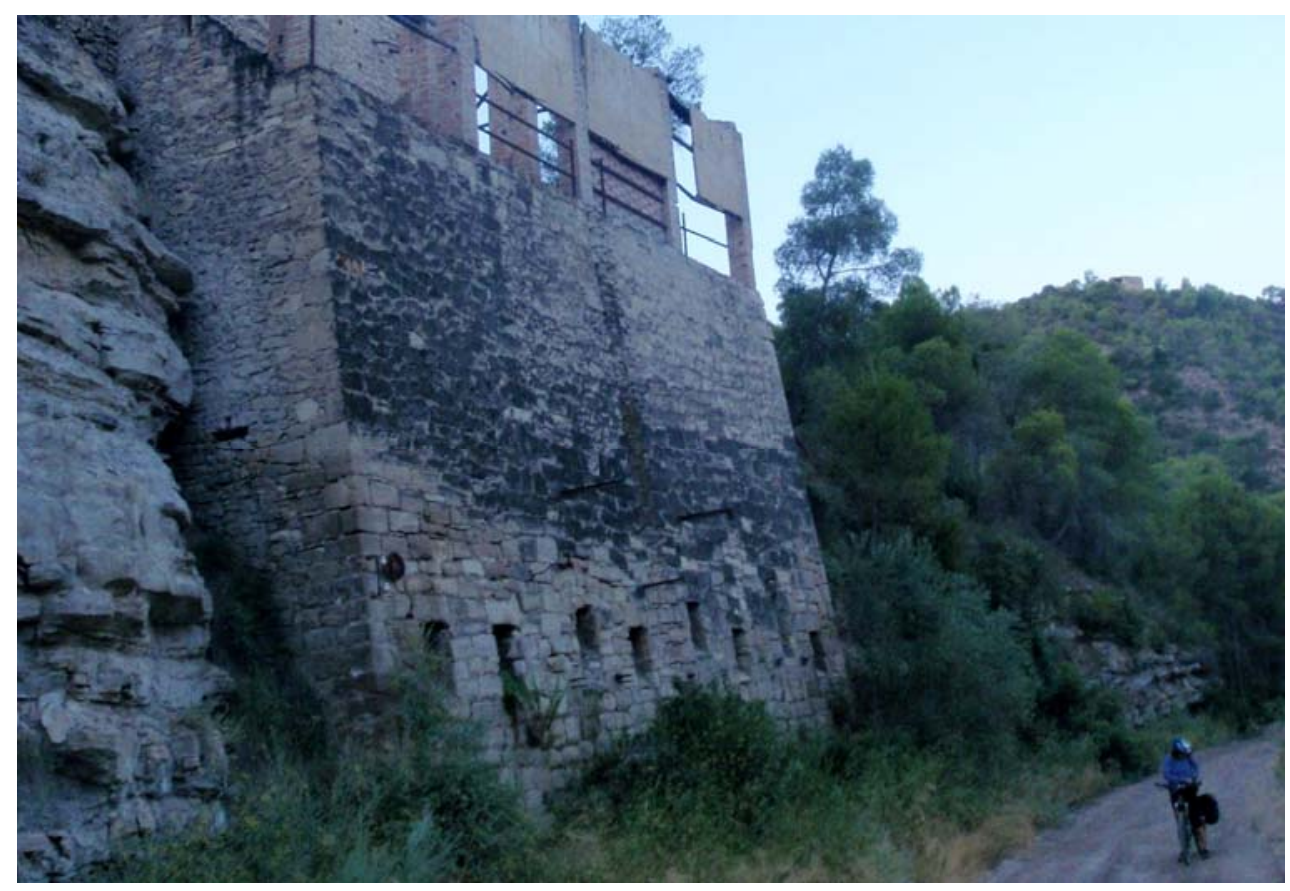

Fotografia 8. Mina de lignit de les Basses.

https://www.google.es/search?q=MINA+DE+LIGNIT+DE+LES+BASSES

En aquest indret finalitza el recorregut de l'itinerari.

Xaragall.2014 n.12 | Recorregut de recerca geològica i geoambiental per la comarca de l'Anoia (Alta Segarra), tot fent una fillola final pel Solsonès: des dels Prats de Rei a Calaf, Durfort, Aleny, Sant Pesselaç i a les Basses 


\section{Bibliografia}

GUIMERÀ, J. et altri (1992).- Geologia (II), Història Natural dels Països Catalans, Vol.2, 547 pag. Enciclopèdia Catalana, S.A. Barcelona.

MATA - PERELLÓ, J.M. (1985).- Depressió de l'Ebre ?, Depressió Central ?. Revista Dovella, $\mathrm{n}^{\circ} 15$, pp.. $45-48$. Manresa.

MATA-PERELLÓ, J.M. (1990).- Inventari Mineralògic de la comarca d'Anoia. Revista Xaragall, $\mathrm{n}^{\circ} 24,40$ pag. Manresa.

MATA-PERELLÓ, J.M. (1991).- Els Minerals de Catalunya. Arxius de la Secció de Ciències, t. XCIII, 442 pag. Institut d’Estudis Catalans. Barcelona.

MATA-PERELLÓ, J.M. (1996).- Recerca geològica i mineralògica per I'Anoia, la Segarra i el Solsonès: de Calaf a la Molsosa i a Torà. Algeps, sèrie $B, n^{\circ} 9,11$ pàg. Manresa.

MATA-PERELLÓ, J.M. (1997).- Recorregut de recerca geològica i mineralògica per la Segarra i per l'Alta Segarra (Anoia): des de Sant Martí de Sesgueioles a Calaf i a Torà de Riubregós. Inèdit, 17 pàgines. Manresa.

MATA-PERELLÓ, J.M. (1999a).- Recerca geològica per les comarques del Bages i de I'Anoia: des de Castellfollit de Riubregós a Rajadell i a Calaf. Algeps, sèrie $B, \mathrm{n}^{\circ} 118,11$ pàgines. Manresa.

MATA-PERELLÓ, J.M. (1999b).- Recorregut de recerca geològica i mineralògica per les comarques del Bages, Alta Segarra i Anoia. Des de Rajadell a Calaf i a Ivorra, Inèdit. 14 pàg. Manresa.

MATA-PERELLÓ, J.M. (2005).- Recerca geològica, minera i mineralògica per les comarques de I'Alta Segarra (Anoia) i de la Segarra: des de sant Martí de Sesgueioles a Calaf; i des de Durfort a Sant Ramon. Inèdit. 8 pag. Manresa.

MATA-PERELLÓ, J.M. (2007a).- Recorregut de recerca geològica, minera i mineralògica per les comarques de l'Alta Segarra (Anoia) i de la Segarra: des de Sant Martí de Sesgueioles a Calaf; i des de Durfort a Castellfollit de Riubregós, Ivorra i a Sant Ramon. Inèdit. 8 pàgines. Manresa.

MATA-PERELLÓ, J.M. (2007b).- Recorregut de recerca geològica, minera i mineralògica per les comarques de l'Anoia, l'Alta Segarra calafina (Anoia) i de la Segarra: des de la Panadella a Sant Martí de Sesgueioles, Calaf, Durfort i a Castellfollit de Riubregós. Inèdit. 10 pàgines. Manresa.

MATA-PERELLÓ, J.M. (2010).- Recorregut de recerca geològica, minera i mineralògica per les comarques de l'Alta Segarra Calafina (Anoia) i de la Segarra: des de Sant Martí de Sesgueioles a Calaf; i de Durfort a Castellfollit de Riubregós, Torà de Riubregós i a Ivorra. Inèdit. 16 pàgines. Manresa.

MATA-PERELLÓ, J.M. (2011).- Recorregut de recerca geològica, minera i mineralògica per la comarca de I'Alta Segarra Calafina (Anoia): des de Sant Martí de Sesgueioles a Calaf; i des de Durfort a Castellfollit de Riubregós. Inèdit. 12 pàgines. Manresa.

MATA-PERELLÓ, J.M. (2014).- Recorregut de recerca geològica i geoambiental per la comarca d'Anoia: des d'Igualada a la Serra de Rubió, Sant Martí de Maçana, la Manresana i als Prats de Rei. Inèdit. 14 pàgines. Manresa. 
XAPAGAL Revista de Ciències de la Catalunya Central

RIBA, O. et altri (1976).- Geografia Física dels Països Catalans, Edit. Ketres, 254 pàgines. Barcelona. 